\title{
Thyroid autoimmunity and miscarriage
}

\author{
Athina Kaprara, Gerasimos E. Krassas \\ Department of Endocrinology, Diabetes and Metabolism, "Panagia" General Hospital, Thessaloniki, Greece
}

\begin{abstract}
The relation of thyroid autoimmunity to miscarriage is an important issue that has attracted the interest of many investigators. A number of papers have been published so far, which include healthy women, women with recurrent miscarriage and those undergoing assisted reproductive techniques. Most studies have shown a significant positive association between the presence of thyroid autoantibodies and miscarriage rate. It is of interest that women with high titers do not show a higher miscarriage rate when compared with women having low titers, although, there is no general agreement on this issue. There are three possible explanations for the assumed association of thyroid autoimmunity with miscarriage: 1) pregnancy loss is an epiphenomenon and not a direct effect of the thyroid autoantibodies, the presence of thyroid autoantibodies reflecting a generalized activation of the immune system; 2 ) delayed conception from the presence of thyroid autoantibodies; hence, when women with thyroid autoimmunity become pregnant, face a higher risk of miscarriage because of older age; and 3) the pregnancy loss is secondary to a subtle deficiency in thyroid hormone concentrations or a lower capacity of the thyroid to adequately adapt to the demands of pregnancy.
\end{abstract}

Key words: Autoimmunity, Miscarriage, Pregnancy loss, Thyroid

\section{INTRODUCTION}

Spontaneous pregnancy loss is a common clinical problem. With the use of sensitive human chorionic gonadotropin (hCG) assays, it has been shown that $31 \%$ of pregnancies end in a miscarriage, with two-thirds of the losses occurring before clinical detection. ${ }^{1,2}$ In approximately $50 \%$ of women with habitual abortions,

Address for correspondence:

Athina Kaprara, Department of Endocrinology, Diabetes and Metabolism, Panagia General Hospital, 22 N. Plastira Str.,

GR-55132 N. Krini, Thessaloniki, Greece,

Tel: +302310479632

e-mail: athkap@yahoo.gr

Received 01-11-07, Revised 05-06-08, Accepted 10-07-08 defined as three or more spontaneous miscarriages, the etiology remains elusive. ${ }^{3}$ Previous studies have suggested that anatomical, hormonal, thrombotic, genetic, infectious, autoimmune, environmental and other unrecognised factors may be involved. ${ }^{4}$ Diseases of the thyroid gland such as hypo- and hyperthyroidism have also been associated with fetal loss. Over the past decade, many reports have linked thyroid autoimmunity (TA) with recurrent abortions and it has been suggested that thyroid autoantibodies may serve as a marker for at-risk pregnancies..$^{5-7}$

Furthermore, it was recently shown that thyroxine administration to pregnant women with positive thyroid autoantibodies and a history of recurrent abortions may improve the final outcome. ${ }^{8}$ 
In this communication, an overview of recent knowledge regarding TA and miscarriage is presented.

\section{AUTOIMMUNE DISEASES AND MISCARRIAGE}

Pregnancy affects the immune system in such a way as to maintain the fetal-maternal allograft, which displays paternal antigens. ${ }^{9}$ Autoimmune diseases (ADs), such as rheumatoid arthritis, psoriatic arthritis and possibly ankylosing spondylitis, may show clinical improvement during pregnancy. ${ }^{10}$ However, recurrent miscarriage has been associated with several ADs. The first such case report suggesting this correlation was published in 1975 and described the presence of a circulating anticoagulant in a woman with recurrent abortions. ${ }^{11}$ This anticoagulant was later found to be the lupus anticoagulant. Since that time many studies have confirmed the association of ADs such as antiphospholipid syndrome,${ }^{12}$ rheumatoid arthritis ${ }^{13}$ and systemic lupus erythematosus, ${ }^{14,15}$ with miscarriage. Thus, antiphospholipid syndrome and systemic lupus erythematosus carry a miscarriage rate of $7-8$ and $22 \%$, respectively, with a higher risk for fetal death after the first trimester. ${ }^{16}$

A number of studies have linked TA with recurrent abortions, although the mechanism involved is not clear. It is postulated that the presence of thyroid autoantibodies reflects a generalized activation of the immune system and a generally heightened autoimmune reactivity against the feto-placental unit. ${ }^{7}$ Thus in 1990, Stagnaro-Green et $\mathrm{al}^{7}$ screening 552 women in the first trimester of pregnancy for thyroid autoantibodies were the first to report a doubling of the miscarriage rate in women who were antibody positive in the first trimester as compared to an antibody negative cohort $(17 \%$ vs $8.4 \%, \mathrm{p}=0.011)$. The miscarriage rate was found to be independent of demographic data, serum TSH level, thyroid antibody titer, prior obstetrical history, maternal age or presence of anticardiolipin antibodies. However, as noted by Abramson et al, ${ }^{17} 10.3 \%$ of the study population was lost to follow-up, while other causes of abortion were not excluded.

Glinoer et $\mathrm{al}^{18}$ documented a four-fold increase in the rate of pregnancy loss in euthyroid women with thyroid autoantibodies compared to thyroid autoantibodies negative pregnant women $(13.3 \%$ vs $3.3 \%, \mathrm{p}<0.001)$.

Lejeune et $\mathrm{al}^{19}$ evaluated 363 women in the first trimester of their pregnancy, 21 of whom spontaneously miscarried. In this cohort, $22 \%$ with positive thyroid antibodies aborted compared to $5 \%$ with antibody negative $(\mathrm{p}<0.005)$. The miscarriages associated with thyroid autoimmunity took place early, within the first trimester of pregnancy.

In the study of Pratt et al, ${ }^{20} 45$ women with recurrent abortions were evaluated for the presence of thyroid autoantibodies as well as for 15 non-organspecific autoantibodies. The women with habitual miscarriages did not have significantly higher incidence of thyroid autoantibodies as compared to the controls ( $31 \%$ vs $19 \%$ ). In a follow-up study in which pregnancy outcome was evaluated in 42 euthyroid women with a history of three or more consecutive, first trimester abortions, $31 \%$ had thyroid autoantibodies. The presence of thyroid autoantibodies before conception carried a significantly increased risk of miscarriage, because 8 of 13 thyroid autoantibody positive women and only 4 of 29 thyroid autoantibody negative women miscarried $(62 \%$ vs $14 \%, \mathrm{p}=0.003){ }^{21}$

Singh et $\mathrm{al}^{5}$ studied 487 women who conceived with assisted reproductive techniques. Twenty-two per cent of them were positive for either TPOAbs or TgAbs or both. It was found that determining the presence of thyroid autoantibodies 14 days after embryo transfer was useful in identifying women at risk for miscarriage after the pregnancy was clinically recognized (visualization of gestation sac) but not before. There was significant statistical difference in clinical miscarriage rate between the antibody positive group (32\%) compared to the antibody negative one $(16 \%)$

In a study ${ }^{6}$ of 22 euthyroid non-pregnant habitual aborters it was found that thyroid autoantibodies were significantly higher compared to two control groups: 22 multigravidae and 22 nulligravidae (36\% vs $5 \%$ and $9 \%$, respectively). It was also shown that 11 of 28 women with recurrent abortions were thyroid antibody positive, as compared to 2 of 28 controls $(39 \%$ vs $7 \%, \mathrm{p}<0.004) .{ }^{22}$

In 45 women with recurrent abortions and 15 con- 
trols, Roussev et $\mathrm{al}^{23}$ found that $9 \%$ of the women in the recurrent abortion group were thyroid antibody positive as contrasted to $0 \%$ in the controls.

Roberts et $\mathrm{al}^{24}$ compared 11 women with a history of recurrent abortions with four other groups (10 non-pregnant controls, 11 healthy pregnant women, 11 women with spontaneous abortion and 10 women with elective termination of pregnancy). They found a statistically significant increase in the rate of thyroid autoantibodies in the group with recurrent pregnancy loss. No information for TA was available before pregnancy.

Iijima et $\mathrm{al}^{25}$ showed that women positive for thyroid autoantibodies had a higher miscarriage rate than women who were negative (10.4 vs $5.5 \%$, $\mathrm{p}<0.05)$. The titer of the thyroid autoantibodies had no effect.

In 74 women with recurrent abortion and in 75 controls it was shown ${ }^{26}$ that women with a history of recurrent pregnancy loss were no more likely than controls to have thyroid autoantibodies. The conclusions of this study have been questioned due to the unusually high incidence of thyroid autoantibodies in the control group (37\%). ${ }^{17,27,28}$

In women undergoing in vitro fertilization (IVF), Kim et $\mathrm{al}^{29}$ found that the miscarriage rate was significantly higher in the group of 28 women who were positive for thyroid autoantibodies compared with the control group ( $40 \%$ vs $11.4 \%, \mathrm{p}<0.05$ ).

Kutteh et $\mathrm{al}^{27}$ investigated 1588 women who were divided into 3 groups: 700 women with two or more consecutive pregnancy losses, 688 with a history of infertility who underwent assisted reproductive techniques and 200 control women. The percentage of women with thyroid autoantibodies was significantly higher in the abortion group compared with the controls $(22.5 \%$ vs $14.5 \%, \mathrm{p}=0.01)$.

Muller et $\mathrm{a}^{30}$ found no difference between antibody negative and antibody positive women regarding miscarriage rate.

Dendrinos et $\mathrm{al}^{31}$ found that $37 \%$ of women with recurrent abortions had positive thyroid autoantibodies compared with $13 \%$ of controls $(\mathrm{p}<0.05)$.

Mecacci et $\mathrm{al}^{32}$ found $37.9 \%$ of 29 women with a history of early pregnancy loss had positive thyroid antibodies.

In a study ${ }^{33}$ of 870 women, thyroid autoantibodies were found in $19 \%$ (TgAbs 5\%, TPOAbs $60 \%$ and both Abs 35\%). Fifty-eight per cent of pregnancies in women with thyroid positive autoantibodies and $58 \%$ of the thyroid negative pregnancies resulted in live births. They concluded that future risk of pregnancy loss in women with unexplained recurrent miscarriages is not affected by their thyroid antibody status.

In a prospective study, Bagis et $\mathrm{al}^{34}$ evaluated 876 women who were followed during their pregnancy starting on the $12^{\text {th }}$ week and subsequently up to one year post partum. In the total group $12.3 \%$ of women were thyroid autoantibody positive. In the antibody positive group, 54 women $(50 \%)$ had at least one previous miscarriage and 12 of them $(11.1 \%)$ had more than 2 , as compared to $14.1 \%$ and $3.1 \%$, respectively, of women who were thyroid autoantibody negative $(\mathrm{p}<0.001)$. The women who were antibody positive had a significantly higher TSH and lower free thyroxine, as compared to women with negative thyroid autoantibodies.

Poppe et $\mathrm{al}^{35}$ evaluated 234 women presenting for their first IVF cycle and found that the miscarriage rate was significantly higher in the thyroid antibody positive women as contrasted to thyroid antibody negative women $(53 \%$ vs $23 \%, \mathrm{p}=0.016)$.

Sieiro Netto et $\mathrm{al}^{36}$ in a study of 534 pregnant women found that $5.4 \%$ of them were thyroid autoantibody positive. The risk of miscarriage was significantly higher among thyroid autoantibody positive women $(10.3 \%)$ and especially among those presenting high TSH levels (12.5\%).

In 984 euthyroid pregnant women Negro et $\mathrm{al}^{37}$ found that the miscarriage rate was $13.8 \%$ in the thyroid autoantibody positive group and $2.4 \%$ in the antibody negative group $(\mathrm{p}<0.05)$.

In a retrospective study ${ }^{38}$ of 416 euthyroid women undergoing assisted reproduction technologies $10.1 \%$ had thyroid autoantibodies. The miscarriage rate was 23.8 in the thyroid autoantibody positive group and $11.5 \%$ in the thyroid autoantibody negative group. The conclusion of this study was that in euthyroid women undergoing assisted reproduction technologies, 
the delivery rates were not affected by the presence of thyroid autoantibodies. However, in women with autoimmune thyroid disease, high-normal TSH values were associated with increased risk of miscarriage.

Thus most of the published studies indicate an association between positive thyroid autoantibodies and miscarriage. A summary of pertinent studies is presented in Tables 1 and 2. There are limited data on the relationship between thyroid autoantibody titers and miscarriage rate and these are controversial. Two such studies have found no correlation, ${ }^{7,25}$ while one study had different results. ${ }^{39}$

\section{POSSIBLE PATHOPHYSIOLOGICAL MECHANISMS OF THE ASSOCIATION OF THYROID AUTOIMMUNITY WITH MISCARRIAGE}

The exact mechanism of an association of thyroid autoimmunity with miscarriage remains largely unknown. Three mechanisms have been postulated. ${ }^{40,41}$ 1) The presence of thyroid autoantibodies reflects a generalized activation of the immune system and specifically a heightened reactivity of the immune system against the feto-placental unit; ${ }^{7}$ women with thyroid autoantibodies could have a more generalized immune imbalance. It must be noted that, pertinent studies have shown that in the presence of antiphospholipid antibodies, miscarriages occur at 22 weeks, ${ }^{42}$ whereas miscarriages in women with positive thyroid autoantibodies occur within the first trimester of gestation ${ }^{35}$ when the fetus is critically dependent on maternal thyroid hormones. ${ }^{43}$ It is of interest that in mice a direct action of $\mathrm{TgAbs}$ on the placenta has been described, but analogous data in humans are not available. ${ }^{44-46}$ 2) The presence of thyroid autoantibodies may act as an infertility factor and may delay conception. Thus, when women with thyroid autoantibodies do become pregnant, they are older and face a higher risk of miscarriage..$^{19,47,48}$ The study of Poppe et $\mathrm{al},{ }^{35}$ showed that age was an independent risk factor for miscarriage. However, the mean age of the thyroid autoantibody positive women was not significantly different from that of thyroid autoanti-

Table 1. Studies published to date regarding the relationship between recurrent miscarriage and thyroid autoimmunity

\begin{tabular}{|c|c|c|c|c|c|c|c|c|}
\hline $\mathbf{A} / \mathbf{A}$ & $\begin{array}{c}\text { Name of first } \\
\text { author } \\
\left(\text { Ref } N^{0}\right)\end{array}$ & $\begin{array}{c}\text { Year of } \\
\text { publication }\end{array}$ & $\begin{array}{c}\text { Number of } \\
\text { TPOAb(+) } \\
\text { women }\end{array}$ & $\begin{array}{c}\text { Number of } \\
\text { TPOAb(-) } \\
\text { women }\end{array}$ & $\begin{array}{c}\text { Age at } \\
\text { detection of } \\
\text { TPOAb }(+)\end{array}$ & $\begin{array}{c}\text { Age at } \\
\text { detection of } \\
\text { TPOAb(-) }\end{array}$ & $\begin{array}{c}\text { Miscarriage rate } \\
\text { in } \operatorname{TPOAB}(+) \\
\text { vs } \operatorname{TPOAb}(-)\end{array}$ & $\mathbf{P}$ \\
\hline 1 & Stagnaro-Green et al ${ }^{(7)}$ & 1990 & 100 & 392 & NA & NA & $17.0 \%$ vs $8.4 \%$ & 0.011 \\
\hline 2 & Glinoer et $\mathrm{al}^{(18)}$ & 1991 & 45 & 603 & $29.0 \pm 1.0$ & $27.0 \pm 1.0$ & 13.3 vs 3.3 & $<0.001$ \\
\hline 3 & Lejeune et $\mathrm{al}^{(19)}$ & 1993 & 23 & 340 & $28.2 \pm 9.5$ & $27.2 \pm 6.8$ & $22.0 \%$ vs $5.0 \%$ & $<0.005$ \\
\hline 4 & Pratt et al ${ }^{(21)}$ & 1993 & 13 & 29 & $33.0 \pm 2.9$ & $34.0 \pm 3.4$ & $64.0 \%$ vs $14.0 \%$ & 0.003 \\
\hline 5 & Singh et $\mathrm{al}^{(5)}$ & 1995 & 106 & 381 & NA & NA & $32.0 \%$ vs $16.0 \%$ & NA \\
\hline 6 & Iijima et al ${ }^{(25)}$ & 1997 & 125 & 951 & $30.2 \pm 4.8$ & $30.0 \pm 4.3$ & $10.4 \%$ vs $5.5 \%$ & $<0.05$ \\
\hline 7 & Kim et $\mathrm{al}^{(29)}$ & 1998 & 28 & 51 & $32.1 \pm 3.7$ & $31.6 \pm 3.1$ & $40.0 \%$ vs $11.4 \%$ & $<0.05$ \\
\hline 8 & Muller et $\mathrm{al}^{(30)}$ & 1999 & 25 & 148 & $32.4 \pm 3.3$ & $32.4 \pm 4.4$ & $33.0 \%$ vs $19.0 \%$ & 0.29 \\
\hline 9 & Rushworth et $\mathrm{al}^{(33)}$ & 2000 & 24 & 81 & $34(20-41)$ & $34(22-46)$ & $42.0 \%$ vs $42.0 \%$ & NA \\
\hline 10 & Bagis et $\mathrm{al}^{(34)}$ & 2001 & 108 & 768 & $27.7 \pm 6.2$ & $25.9 \pm 5.2$ & $11.1 \%$ vs $3.1 \%$ & $<0.0001$ \\
\hline 11 & Poppe et $\mathrm{al}^{(35)}$ & 2003 & 32 & 202 & $33.2 \pm 4.6$ & $31.6 \pm 5.4$ & $53.0 \%$ vs $23.0 \%$ & 0.016 \\
\hline 12 & Sieiro Netto et $\mathrm{al}^{(36)}$ & 2004 & 29 & 505 & NA & NA & $10.3 \%$ vs $2.0 \%$ & 0.029 \\
\hline 13 & Negro et $\mathrm{al}^{(37)}$ & 2006 & $58^{\mathrm{b}}$ & 869 & $30.0 \pm 6.0$ & $28.0 \pm 5.0$ & $\begin{array}{c}3.5^{\mathrm{a}} \text { vs } 13.8^{\mathrm{b}} \\
\text { vs } \\
2.4 \%\end{array}$ & $\begin{array}{c}<0.05 \text { between } \\
\text { control and } \\
\text { subgroup } b\end{array}$ \\
\hline 14 & Negro et $\mathrm{al}^{(38)}$ & 2007 & 21 & 234 & NA & NA & $23.8 \%$ vs $11.5 \%$ & NA \\
\hline
\end{tabular}

NA: Not Available, a: Subgroup given LT4, b: Subgroup not given LT4 
Table 2. Studies published to date on the rate of positive thyroid autoantibodies in women with recurrent miscarriage and controls.

\begin{tabular}{|c|c|c|c|c|c|c|c|c|}
\hline $\mathbf{A} / \mathbf{A}$ & $\begin{array}{c}\text { Name of first } \\
\text { author }\left(\text { Ref } \mathbf{N}^{0}\right)\end{array}$ & $\begin{array}{c}\text { Year of } \\
\text { publication }\end{array}$ & $\begin{array}{l}\text { Number of women } \\
\text { with RSM }\end{array}$ & $\begin{array}{c}\text { Number } \\
\text { of controls }\end{array}$ & $\begin{array}{l}\text { Age of women } \\
\text { with RSM }\end{array}$ & $\begin{array}{l}\text { Age of } \\
\text { controls }\end{array}$ & $\begin{array}{l}\text { Rate of TPOAbs in women } \\
\text { with RSM vs controls }\end{array}$ & $\mathbf{P}$ \\
\hline 1 & Pratt et al ${ }^{(20)}$ & 1993 & 45 & 100 & $35.5 \pm 0.68$ & $37.5 \pm 12.2$ & $31.0 \%$ vs $19.0 \%$ & $\overline{\mathrm{NA}}$ \\
\hline 2 & Bussen et $\mathrm{al}^{(6)}$ & 1995 & 22 & $\begin{array}{l}22^{\mathrm{a}} \\
22^{\mathrm{b}}\end{array}$ & $30.5 \pm 4.6$ & $\begin{array}{l}29.0 \pm 4.7 \\
32.5 \pm 5.1\end{array}$ & $\begin{array}{l}36.0 \% \text { vs } 9.0 \% \text { and } \\
5.0 \% \text {, respectively }\end{array}$ & $\begin{array}{c}0.03 \\
0.009\end{array}$ \\
\hline 3 & Roussev et $\mathrm{al}^{(23)}$ & 1996 & 45 & 15 & NA & NA & $9.0 \%$ vs $0 \%$ & NA \\
\hline 4 & Roberts et $\mathrm{al}^{(24)}$ & 1996 & 11 & $\begin{array}{l}10^{\mathrm{c}} \\
11^{\mathrm{d}} \\
11^{\mathrm{e}} \\
10^{\mathrm{f}}\end{array}$ & $30.4 \pm 4.8$ & $\begin{array}{l}28.4 \pm 3.2 \\
24.5 \pm 4.1 \\
25.5 \pm 3.8 \\
25.7 \pm 6.9\end{array}$ & $36.3 \%$ vs $4.7 \%$ & $<0.01$ \\
\hline 5 & Bussen et $\mathrm{al}^{(22)}$ & 1997 & 28 & 28 & $32.4 \pm 4.5$ & $31.2 \pm 5.9$ & $39.0 \%$ vs $7.0 \%$ & 0.004 \\
\hline 6 & Esplin et $\mathrm{al}^{(26)}$ & 1998 & 74 & 75 & $33.6 \pm 6.9$ & $38.6 \pm 5.6$ & $29.0 \%$ vs $37.0 \%$ & $>0.05$ \\
\hline 7 & Kutteh et al ${ }^{(27)}$ & 1999 & 700 & 200 & $33.3 \pm 5.0$ & $30.8 \pm 6,2$ & 22.5 vs $14.5 \%$ & 0.01 \\
\hline 8 & Dendrinos et al ${ }^{(31)}$ & 2000 & 30 & 15 & $25-37$ & $26-36$ & $37.0 \%$ vs $13.0 \%$ & $<0.05$ \\
\hline 9 & Mecacci et $\mathrm{al}^{(32)}$ & 2000 & 29 & 69 & $33.7 \pm 0.8$ & $33.7 \pm 0.8$ & $37.9 \%$ vs $14.5 \%$ & $<0.02$ \\
\hline
\end{tabular}

RSM: recurrent spontaneous miscarriage, NA: Not Available, a: nulligravidae, b: multigravidae, c: non-pregnant women, d: healthy women in the first trimester of an ongoing pregnancy, e: women admitted with spontaneous abortion (no history of recurrent miscarriage), f: healthy women admitted for termination of pregnancy

body negative women. It is of note that the study of Poppe et al is restricted to a specific population, i.e. women scheduled for assisted reproduction, so that age findings from this study cannot be generalized to the whole population of pregnant women. Moreover, Kontiainen et $\mathrm{al}^{49}$ found an increase in the titer of TPOAbs with age, but this correlation was not statistically significant. In a study of Kutteh et al, ${ }^{27}$ a high number of patients with recurrent pregnancy loss demonstrated elevated autoantibody titer as age increased, up until the age range of 31-35, after which a decreased frequency was observed. 3) The presence of thyroid autoantibodies in euthyroid women could be associated with a subtle deficiency in thyroid hormone concentrations or a lower capacity of the thyroid gland to adequately adapt to the demands of pregnancy. Indeed, the mean serum TSH values, while being within normal range, were significantly higher in thyroid autoantibody positive women compared to women with negative thyroid autoantibodies. This may reflect lower thyroidal reserve during pregnancy when a greater amount of thyroid hormones is demanded. ${ }^{50}$ Moreover, it was shown that in thyroid autoantibody positive women, serum TSH levels gradually increased as gestation progressed, with $19 \%$ of them having an increased serum TSH at delivery. Serum TSH levels also increased in the group with negative thyroid autoantibodies but to a lesser extent. ${ }^{37,51}$

Imaizumi et $\mathrm{al}^{45}$ investigated the impact of experimentally induced thyroiditis on pregnancy loss in a murine model. The immunized mice that mated with a similar but not identical strain had a significantly lower percentage of pregnancy maintenance $(57 \%)$ as compared with the immunized mice that mated with an identical strain $(98 \%, \mathrm{p}<0.05)$. Moreover, Matalon et $\mathrm{al}^{46}$ expanding on the findings by Imaizumi et al revealed an increase in fetal wastage $(p=0.04)$ and decrease in fetal and placental weights $(p<0.001)$ in the immunized mice.

The various explanations stated above are not in contradiction with one another. It is possible that the increased risk of miscarriage in thyroid antibody positive women results from several influences acting in concert. 


\section{THE EFFECT OF THYROXINE ADMINISTRATION ON MISCARRIAGE RATE IN WOMEN WITH POSITIVE THYROID AUTOANTIBODIES}

It is obvious that the final goal of clinicians and researchers is to decrease miscarriage rate in women with thyroid autoimmunity to that of the general population. Autoimmunity may play a major role in fertilization, implantation and placenta development.

Therapeutic interventions aiming at modulating the immune system of women with autoantibodies have included intravenous immunoglobulin administration. This treatment resulted in an increase in the percentage of women who had successful pregnancies. ${ }^{52,53}$ In addition to this, the combination of immunoglobulin, heparin and aspirin had better results than the administration of only heparin and aspirin. ${ }^{54}$

The first study in which thyroid hormone replacement therapy was applied was conducted by Vaquero et al. ${ }^{8}$ It was a prospective study in women with two or more previous first trimester miscarriages and positive thyroid autoantibodies. Eleven women were treated with intravenous immunoglobulin during pregnancy and 16 women were treated with thyroid hormone replacement therapy (66 mg of thyroid extract, started before conception and continued until the $20^{\text {th }}$ week). The conclusion was that thyroid hormone supplementation was more effective than intravenous immunoglobulin in the prevention of recurrent abortions. Indeed, $81.2 \%$ of the women treated with thyroid extract had a successful pregnancy outcome contrasted to $54.5 \%$ of the group treated with immunoglobulin $(\mathrm{p}<0.05)$. However, it has been argued that the number of patients was small and that the thyroid extract administration was initiated before conception in contrast to the administration of intravenous immunoglobulin that was initiated after the onset of pregnancy. ${ }^{55}$

Negro et $\mathrm{a}^{56}$ also reported results on levothyroxine (LT4) administration to euthyroid women who underwent IVF and were thyroid autoantibody positive. The women were randomly divided into two groups. One received LT4 and the other placebo. The miscarriage rate in the untreated group was $52 \%$ compared to $33 \%$ in the group in which LT4 was given. However, the difference was not statistically significant, most probably because the number of patients investigated was small.

In another study, Negro et $\mathrm{al}^{37}$ divided thyroid autoantibody positive women into two groups. One group was treated with LT4 $(49.7 \pm 14 \mu \mathrm{g}$ daily) in a dose based on the TSH starting values. The other group was not treated. A third group served as a normal general population control. Forty percent of the women in the treated group started LT4 treatment by the $8^{\text {th }}$ week and $79 \%$ by the $12^{\text {th }}$ week. Initially, the mean TSH values were significantly higher in the treated and untreated groups compared to the control group (1.6 \pm 0.5 and $1.7 \pm 0.4$, respectively vs $1.1 \pm 0.4$ $\mathrm{mU} / \mathrm{L}, \mathrm{p}<0.05$ and $\mathrm{p}<0.05$, respectively). The TSH values of the untreated group remained significantly higher than those of the other 2 groups during the entire gestational period. TSH and FT4 values in the treated group were not significantly different from the control group. The treated group and the controls showed a similar miscarriage rate $3.5 \%$ and $2.4 \%$, respectively), which was lower than that of the second group who did not receive LT4 $(13.8 \%, \mathrm{p}<0.05) .{ }^{37}$ The conclusion of this study was that thyroid autoantibody positive women have an increased risk of miscarriage but when given the benefit of treatment with thyroid hormone, they behave as the normal ones.

It is not entirely clear whether the development of hypothyroidism can be predicted at the beginning of gestation. Glinoer et $\mathrm{al}^{57}$ mentioned that women who developed hypothyroidism had higher TPOAb titers at delivery and in the first trimester and a slightly but significantly higher TSH level at the beginning of their pregnancy compared to women with autoimmune thyroid disease who maintained normal thyroid function during pregnancy. They therefore suggested that women with TPOAb titers greater than $2000 \mathrm{U} / \mathrm{ml}$ or $\mathrm{TSH}$ greater than $2 \mathrm{mU} / \mathrm{ml}$ require close monitoring during gestation and probably systematic treatment with thyroid hormones. In a recent study, Negro et $\mathrm{al}^{138}$ stressed that, at least for TPOAb positive women desiring pregnancy, TSH value $>2.5 \mathrm{mU} / \mathrm{L}$ is to be considered abnormal.

Thyroxine administration seems to be effective in reducing the number of miscarriages when given during the early stages of pregnancy, because miscar- 
riages with maternal thyroid autoimmunity generally occur within the first trimester. Nevertheless, in a study carried out in infertile women undergoing assisted reproduction technologies, LT4 treatment was not found to be beneficial. ${ }^{56}$

Poppe and Glinoer have proposed that serum $\mathrm{TSH}$, free T4 and thyroid autoantibodies should be measured in early gestation. When serum TSH is elevated or free T4 is below normal, LT4 should be administered during pregnancy. In women with thyroid autoantibodies and serum $\mathrm{TSH}<2 \mathrm{mU} / \mathrm{L}$, LT4 treatment is not warranted; however, serum $\mathrm{TSH}$ and free T4 should be measured later in gestation, preferably at the end of the second trimester. For women with thyroid autoantibodies and TSH between 2-4 mU/1 in early gestation, treatment with LT4 should be considered. It is important to consider that serum TSH is down-regulated during the first half of gestation by hCG. ${ }^{28}$

It has to be mentioned that other substances, such as selenium, that are essential to thyroid hormonogenesis may play a role in repeated miscarriages. It has been reported that selenium administration during pregnancy decreases thyroid autoantibodies concentration..$^{58}$

Over the past fifteen years a positive association between thyroid autoantibodies and fetal loss in unselected women has been clearly established. Recent studies, although limited in number and not well designed, have suggested that thyroxine therapy in women with thyroid autoantibodies decreases fetal loss. It is, however, too early to draw final conclusions regarding a very important question, namely if women with positive thyroid autoantibodies should be started on LT4 therapy during their pregnancies to minimize abortion rate. Further studies are needed before we can answer this question.

\section{CONCLUSIONS}

Most but not all studies have shown a significant association between the presence of thyroid antibodies and a higher miscarriage rate. However, patients with high titers of thyroid autoantibodies do not show a higher rate of miscarriages compared with patients with low titers. The mechanisms involved remain speculative.

Regarding prevention of miscarriage, there are a few studies showing that thyroxine treatment may be effective in reducing the number of miscarriages when given during the early stages of pregnancy. Further studies are required with a greater number of women in order to reach definitive conclusions.

\section{REFERENCES}

1. Wilcox AJ, Weinberg GR, O’Connor JF, et al, 1988 Incidence of early loss of pregnancy. N Engl J Med 319: 189-194.

2. Whittaker PG, Taylor A, Lind T, 1983 Unsuspected pregnancy loss in healthy women. Lancet 1: 1126-1127.

3. Matalon ST, Blank M, Ornoy A, Shoenfeld Y, 2001 The association between anti-thyroid antibodies and pregnancy loss. Am J Reprod Immunol 45: 72-77.

4. Stephenson MD, 1996 Frequency of factors associated with habitual abortions in 197 couples. Fertil Steril 66: 24-29.

5. Singh A, Dantas ZN, Stone SC, Asch RH, 1995 Presence of thyroid antibodies in early reproductive failure: biochemical versus clinical pregnancies. Fertil Steril 63: 277-281.

6. Bussen S, Steck T, 1995 Thyroid autoantibodies in euthyroid non-pregnant women with recurrent spontaneous abortions. Hum Reprod 10: 2938-2940.

7. Stagnaro-Green A, Roman SH, Cobin RH, el-Hazary E, Alvarez-Marfany M, Davies TF, 1990 Detection of at-risk pregnancy by means of highly sensitive assays for thyroid autoantibodies. JAMA 264: 1422-1425.

8. Vaquero E, Lazzarin N, Carolis D, Valensise H, Moretti C, Ramanini C, 2000 Mild thyroid abnormalities and recurrent spontaneous abortion: diagnostic and therapeutical approach. Am J Reprod Immunol 43: 204-208.

9. Lazarus JH, Ludgate ME, 1997 Prevention and treatment of postpartum Graves' disease. Baillieres Clin Endocrinol Metab 11: 549-560.

10. Russell AS, 1998 Immune modulation (TH1 and TH2 responses) in pregnancy. Scand J Rheumatol Suppl 107: 14-17.

11. Nilsson IM, Astedt B, Hender U, Bezerin D, 1975 Intrauterine death and circulating anticoagulant "antithromboplastin”. Acta Med Scand 197: 153-159.

12. Cowchock S, Smith JB, Gocial B, 1986 Antibodies to phospholipids and nuclear antigens in patients with repeated abortions. Am J Obstet Gynecol 155: 1002-1010.

13. Kaplan D, 1986 Fetal wastage in patients with rheumatoid arthritis. J Rheumatol 13: 875-877.

14. DeVoe LD, Taylor RL, 1979 Systemic lupus erythematosus in pregnancy. Am J Obstet Gynecol 135: 473-479.

15. Gimovsky ML, Montor M, Paul RH, 1984 Pregnancy 
outcome in women with systemic lupus erythematosus. Obstet Gynecol 63: 686-692.

16. Faussett MB, Branch DW, 2000 Autoimmunity and pregnancy loss. Semin Reprod Med 18: 379-392.

17. Abramson J, Stagnaro-Green A, 2001 Thyroid antibodies and fetal loss: an evolving story. Thyroid 11: 57-63.

18. Glinoer D, Soto MF, Bourdoux P, et al, 1991 Pregnancy in patients with mild thyroid abnormalities: maternal and neonatal repercussions. J Clin Endocrinol Metab 73: 421-427.

19. Lejeune B, Grun JP, de Nayer P, Servais G, Glinoer D, 1993 Antithyroid antibodies underlying thyroid abnormalities and miscarriage or pregnancy induced hypertension. Br J Obstet Gynaecol 100: 669-672.

20. Pratt D, Novotny M, Kaberlein G, Dudkiewicz A, Gleincher N, 1993 Antithyroid antibodies and the association with non-organ-specific antibodies in recurrent pregnancy loss. Am J Obstet Gynecol 168: 837-841.

21. Pratt DE, Kaberlein G, Dudkiewicz A, Karande V, Gleincher N, 1993 The association of antithyroid antibodies in euthyroid nonpregnant women with recurrent first trimester abortions in the next pregnancy. Fertil Steril 60: 1001-1005.

22. Bussen SS, Steck T, 1997 Thyroid antibodies and their relation to antithrombin antibodies, anticardiolipin antibodies and lupus anticoagulant in women with recurrent spontaneous abortions (antithyroid, anticardiolipin and antithrombin autoantibodies and lupus anticoagulant in habitual aborters). Eur J Obstet Gynecol Reprod Biol 74: 139-143.

23. Roussev RG, Kaider BD, Pride DE, Coulam CB, 1996 Laboratory evaluation of women experiencing reproductive failure. Am J Reprod Immunol 35: 415-420.

24. Roberts J, Jenkins C, Wilson R, et al, 1996 Recurrent miscarriage is associated with increased numbers of CD5/20 positive lymphocytes and an increased incidence of thyroid antibodies. Eur J Endocrinol 134: 84-86.

25. Iijima T, Tada H, Hidaka Y, Mitsuda N, Murata Y, Amino N, 1997 Effects of autoantibodies on the course of pregnancy and fetal growth. Obstet Gynaecol 90: 364369.

26. Esplin MS, Branch DW, Silver R, Stagnaro-Green A, 1998 Thyroid autoantibodies are not associated with recurrent pregnancy loss. Am J Obstet Gynaecol 179: 1583-1586.

27. Kutteh WH, Yetman DL, Carr AC, Beck LA, Scott RT Jr, 1999 Increased prevalence of antithyroid antibodies identified in women with recurrent pregnancy loss but not in women undergoing assisted reproduction. Fertil Steril 71: 843-848.

28. Poppe K, Glinoer D, 2003 Thyroid autoimmunity and hypothyroidism before and during pregnancy. Hum Reprod Update 9: 149-161.

29. Kim CH, Chae HD, Kang BM, Chang YS, 1998 Influence of antithyroid antibodies in euthyroid women on in vitro fertilization-embryo transfer outcome. Am J Reprod
Immunol 40: 2-8.

30. Muller AF, Verhoeff A, Mantel MJ, Berghout A, 1999 Thyroid autoimmunity and abortion: a prospective study in women undergoing in vitro fertilization. Fertil Steril 71: 30-34.

31. Dendrinos S, Papasteriades C, Tarassi K, Christodoulakos G, Prasinos G, Creatsas G, 2000 Thyroid autoimmunity in patients with recurrent spontaneous miscarriages. Gynecol Endocrinol 14: 270-274.

32. Mecacci F, Parretti E, Cioni R, et al, 2000 Thyroid autoimmunity and its association with non-organ-specific antibodies and subclinical alterations of thyroid function in women with a history of pregnancy loss or preeclampsia. J Reprod Immunol 46: 39-50.

33. Rushworth FH, Backos M, Rai R, Chilcott IT, Baxter N, Regan L, 2000 Prospective pregnancy outcome in untreated recurrent miscarries with thyroid autoantibodies. Hum Reprod 15: 1637-1639.

34. Bagis T, Gokcel A, Saygili ES, 2001 Autoimmune thyroid disease in pregnancy and the postpartum period: relationship to spontaneous abortion. Thyroid 11: 1049-1053.

35. Poppe K, Glinoer D, Tournaye H, et al, 2003 Assisted reproduction and thyroid autoimmunity: an unfortunate combination? J Clin Endocrinol Metab 88: 4149-4152.

36. Sieiro Netto L, Medina Coeli C, Micmacher E, et al, 2004 Influence of thyroid autoimmunity and maternal age on the risk of miscarriage. Am J Reprod Immunol 52: 312-316.

37. Negro R, Formoso G, Mangieri T, Pezzarossa A, Dazzi D, Hassan H, 2006 Levothyroxine treatment in euthyroid pregnant women with autoimmune thyroid disease: effects on obstetrical complications. J Clin Endocrinol Metab 91: 2587-2591.

38. Negro R, Formoso G, Coppola L, et al, 2007 Euthyroid women with autoimnmune disease undergoing assisted reproduction technologies: The role of autoimmunity and thyroid function. J Endocrinol Invest 30: 3-8.

39. Wilson R, Ling H, MacLean MA, et al, 1999 Thyroid antibody titer and avidity in patients with recurrent miscarriage. Fertil Steril 71: 558-561.

40. Prummel MF, Wiersinga WM, 2004 Thyroid autoimmunity and miscarriage. Eur J Endocrinol 150: 751-755.

41. Stagnaro-Green A, Glinoer D, 2004 Thyroid autoimmunity and the risk of miscarriage. Best Pract Res Clin Endocrinol Metab 18: 167-181.

42. ACOG educational bulletin,1998 Antiphospholipid syndrome. Int J Gynaecol Obstet 61: 193-202.

43. Calvo RM, Jauniaux E, Gulbis B, et al, 2002 Fetal tissues are exposed to biologically relevant free thyroxine concentrations during early phases of development. J Clin Endocrinol Metab 87: 1768-1777.

44. Poppe K, Glinoer D, Tournaye H, et al, 2007 Thyroid autoimmunity and female infertility. In: Wiersinga W, Drexhage H, Weetman A, Butz S (eds) The thyroid and autoimmunity, Georg Thieme Verlag, New York; pp, 143-152. 
45. Imaizumi M, Pritsker A, Kita M, Ahmad L, Unger P, Davies T, 2001 Pregnancy and murine thyroiditis: thyroglobulin immunization leads to fetal loss in specific allogeneic pregnancies. Endocrinology 142: 823-829.

46. Matalon ST, Blank M, Levy Y, et al, 2003 The pathogenic role of anti-thyroglobulin antibody on pregnancy: evidence from an active immunization model in mice. Hum Reprod 18: 1094-1099.

47. Menken J, Trussell J, Larsen U, 1986 Age and infertility. Science 233: 1389-1394.

48. Osmanagaoglu K, Tournaye H, Kolibianakis E, Camus M, van Steirteghem A, Devroey P, 2002 Cumulative delivery rates after ICSI in women aged $>37$ years. Hum Reprod 17: 940-944.

49. Kontiainen S, Melamies L, Miettinen A, et al, 1994 Thyroid autoantibodies in serum samples with abnormal TSH levels. APMIS 102: 716-720.

50. Lazarus JH, Kokandi A, 2000 Thyroid disease in relation to pregnancy: A decade of change. Clin Endocrinol (Oxf) 53: 265-278.

51. Glinoer D, 2006 Editorial: Miscarriage in women with positive anti-TPO antibodies: Is thyroxine the answer? J Clin Endocrinol Metab 91: 2500-2502.

52. Kiprov DD, Nachtigall RD, Weaver RC, Jacobson A, Main EK, Garovoy MR, 1996 The use of intravenous immunoglobulin in recurrent pregnancy loss associated with combined alloimmune and autoimmune abnormalities. Am J Reprod Immunol 36: 228-234.
53. Stricker RB, Steinleitner A, Bookoff CN, Weckstein LN, Winger EE, 2000 Successful treatment of immunologic abortion with low-dose intravenous immunoglobulin. Fertil Steril 73: 536-540.

54. Sher G, Maassarani G, Zouves C, et al, 1998 The use of combined heparin/aspirin and immunoglobulin $\mathrm{G}$ therapy in the treatment of in vitro fertilization patients with antithyroid antibodies. Am J Reprod Immunol 39: 223-225.

55. Glinoer D, 2000 Thyroid immunity, thyroid dysfunction, and the risk of miscarriage: a propos article by Vaquero et al. Mild thyroid abnormalities and recurrent spontaneous abortion: diagnostic and therapeutical approach. Am J Reprod Immunol 43: 202-203.

56. Negro R, Mangieri T, Coppola L, et al, 2005 Levothyroxine treatment in thyroid peroxidase antibody-positive women undergoing assisted reproduction technologies: a prospective study. Hum Reprod 20: 1529-1533.

57. Glinoer D, Riahi M, Grun JP, Kinthaert J, 1994 Risk of subclinical hypothyroidism in pregnant women with asymptomatic autoimmune thyroid disorders. J Clin Endocrinol Metab 79: 197-204.

58. Negro R, Greco G, Mangieri T, Pezzarossa A, Dazzi D, Hassan H, 2007 The influence of selenium supplementation on postpartum thyroid status in pregnant women with thyroid peroxidase autoantibodies. J Clin Endocrinol Metab 92: 1263-1268. 